\title{
AC 2012-4255: STEPPING OUTSIDE THE BOX: EDUCATION OF GLOBAL ENGINEERS
}

\author{
Dr. Samuel P. Clemence, Syracuse University
}

Samuel P. Clemence, P.E., Laura J. and L. Douglas Meredith Professor for Teaching Excellence, L.C. Smith College of Engineering and Computer Science, Syracuse University, is a Fellow in the American Society of Civil Engineers, a member of Chi Epsilon and Sigma Xi, and was elected to Tau Beta Pi as an Eminent Engineer in 1977. He has received Outstanding Teacher awards at the University of Missouri, Rolla (1974-75, 1976-77) and at Syracuse University (1988-89). The Division of Higher Education and Ministry of the Methodist Church selected him as the 1990 Scholar/Teacher of the Year at Syracuse University. Clemence received the 1998 Outstanding Educator Award from the St. Lawrence Section of the American Society for Engineering Education. He served as Senior Associate dean of the L.C. Smith College of Engineering and Computer Science from 1991-1996. He is the Editor of three books and author or co-author of more than 60 technical publications. Clemence received his Ph.D. in civil engineering from the Georgia Institute of Technology in 1973. He is a registered Professional Engineer in the state of New York.

\section{Ms. Sharon W. Alestalo, Syracuse University}

Sharon W. Alestalo, M.S., is the Program Director for Syracuse University's Women in Science and Engineering (WISE) program within the Colleges of Engineering \& Computer Science and Arts \& Sciences at Syracuse University. Sharon came to the University with 25 years of practical and executive experience in social action venues and eight years in higher education settings. Her bachelor's and master's degrees are from the University at Albany in sociology and rehabilitation counseling respectively. In addition to managing programs in the academy, Alestalo has worked with adults with a variety of disabilities and with children and families in both service and administrative capacities. During this time, she has developed an expertise in girls and women's issues, cultural competency, managing not-for-profit agencies, and program development and evaluation.

\section{Dr. Shobha K. Bhatia, Syracuse University}

Shobha Bhatia's areas of specialization are geotechnical and geosynthetic engineering. Her research is funded through an extensively funded research program and she has produced more than eighty technical publications in prestigious journals and conference proceedings, invited participation in national and international conferences, as well as key note addresses, short-courses, and service and leadership on numerous technical committees. Bhatia's extensive research has achieved both breadth and depth, ranging from the material characterization of soils to the application of geosynthetics and natural materials in waste containment, road and building construction, and erosion control. She has held numerous offices such as Vice President of the North American Geosynthetics Society (NAGS) and member of the prestigious Technical Committees Council and International Activities Committee Task Force of the Geo-Institute of the American Society of Civil Engineers (ASCE). Her collaborative research is further evidenced by her new vision which brought together the leaders in the field ranging from psychology, management, law, public policy, and sociology to deal with a variety of issues concerning women and leadership. A case in point is the awarding of the ADVANCE Institutional Transformational Award for Women in Engineering Leadership Institute (WELI) (National Science Foundation, May 2003-2006). This multi-institutional proposal was accomplished by Bhatia and other internationally-renowned leaders from Utah University, Iowa University, University of California at Davis, University of Central Florida, Guelph University, and University of Louisiana. The main findings and contributions resulted in a coauthored book entitled "Engineering Women and Leadership," published by Morgan \& Claypool Publisher, La Porte, Co.

\section{Dr. Eric M. Lui, Syracuse University}

Eric M. Lui received his B.S. degree in civil and environmental engineering with high honors from the University of Wisconsin at Madison, Wis., and his M.S. and Ph.D. degrees in civil engineering (with emphasis in structural engineering) from Purdue University, Ind. Since joining the Department of Civil and Environmental Engineering at Syracuse University, Lui has taught a variety of undergraduate and graduate courses in the areas of mechanics of materials, numerical methods, structural analysis and design, and 
green technology and sustainability. He was named a recipient of the College of Engineering and Computer Science Crouse Hinds Award for Excellence in Teaching in 1997, received the College Educator of the Year Award from Technology Alliance of Central New York in 2007, was named the Laura J. and L. Douglas Meredith Professor for Teaching Excellence in 2007, and was awarded the College Faculty Excellence Award in 2009. Furthermore, he is the recipient of the ASCE Committee on Student Services Certificate for Exemplary Services in 2000, has served as the Faculty Advisor of Syracuse University's Chapter of ASCE for more than a decade, and was named recipient of the ASCE Faculty Advisor Reward Program from 2001 to 2003. Lui has been a long-time member of the American Society of Civil Engineers (ASCE), and has served on a number of ASCE publications, technical, and educational committees. He was the Associate Editor (from 1994 to 1997) and later the Book Editor (from 1997 to 2000) for ASCE Journal of Structural Engineering. He is also a member of other professional organizations such as the American Society of Engineering Education, American Institute of Steel Construction, American Concrete Institute, American Academy of Mechanics, and Sigma Xi.

He has been listed in more than ten Who's Who publications, and has served as a consultant for a number of state and local engineering firms.

\section{Dr. Ossama Salem, Syracuse University}

Ossama (Sam) Salem, Ph.D., P.E., CPC, LEED AP, is Yabroudi Chair Professor of sustainable civil infrastructures and professor of construction engineering and management in the Civil and Environmental Engineering Department, L. C. Smith College of Engineering and Computer Science, 151M Link Hall, Syracuse University, Syracuse, NY 13244-1240; Phone: 1-315-443-3401; Fax: 1-315-443-1243; Email: omsalem@syr.edu. Web: http://www.ecs.syr.edu/academic/civilenvironment_eng/cie_faculty.aspx?id=2145.

(C)American Society for Engineering Education, 2012 


\title{
Stepping Outside the Box: Education of Global Engineers
}

\begin{abstract}
Learning to work effectively within the global context of today's world requires both technical and intercultural competency beyond what is gained in a traditional course of study. Global engineers should possess cultural sensitivity and knowledge, as well as the interpersonal skills, to adapt within a variety of cultural contexts and with people that differ from their own experiences. A positive attribute of this intercultural literacy is that designs and solutions are no longer bound within the technical domain, but should be reflective of the engineer's cultural understanding and interpersonal competence. Working closely with the Dubai Contracting Company (DCC) and in collaboration with the Civil and Environmental Engineering Department at Syracuse University, the authors have successfully designed and implemented an innovative program to provide students with distinctive skill sets to enhance their capacity as global civil engineers in real and practical ways through university-industry partnerships and networks. The result is a unique program that engages American and Middle Eastern civil engineering students to work together in a summer internship in Dubai, United Arab Emirates (UAE) at the Dubai Contracting Company (DCC). Through a combination of learning and discussion sessions at corporate headquarters, hands-on experience on actual project sites, and visits to architectural/engineering firms and fabrication/machine shops, students learn the detailed workings of the contracting and construction industry in Dubai and the region. During this time, American and Middle Eastern students also work collaboratively on team projects. By working, learning and living side-by-side with professionals and students from other countries and disciplines, lessons learned in the preinternship seminars focusing on the history, geography, culture, political systems, traditions, languages and customs of the Middle East are reinforced. Thus, the program commendably inculcates the skills and behaviors essential to global competency. Program evaluations show that students are positively influenced by each component; the experience-based learning with an industry partner and the cultural awareness seminars. In addition, the combination of both components unequivocally creates substantial growth in students, especially the myriad of professional skills that go beyond technical expertise and are deemed so critical to professional success in a global world. This paper will discuss the program design, implementation, evaluation results and implications for engineering education and study abroad programs.
\end{abstract}

\section{Introduction}

Globalization has integrated the world in unprecedented ways, engineering - civil and construction engineering in particular - has been at the forefront of these changing dynamics. Pennoni ${ }^{1}$ has shown how globalization influences all aspects of an engineer's ability to compete in the U.S. market, noting that many U.S. engineering firms now maintain offices in foreign and particularly developing countries to increase their growth. Galloway ${ }^{2}$ has pointed out that none of today's construction projects, even those in the United States, are truly domestic, given the 
international engineering firms that they rely upon and the foreign resources involved in financing, materials, equipment, and other engineering technology. There are rapidly emerging demands being placed on engineering and the construction industry as a result of globalization. It is clear that the very idea of the highly competent civil engineer and the successful engineering enterprise depend upon an individual's ability to deepen their expertise in both the engineering and interpersonal/business realms in addition to having a strong foundation for working globally. Engineering educators need to respond to the global paradigm by stepping out of the box to create educational and experiential opportunities beyond the traditional curricula. It is critical that engineering educators seek efficient and effective ways to address the technical, professional and interpersonal competencies essential for practicing in the $21^{\text {st }}$ century global context.

Opportunities to learn and practice essential skills for global engineering should be embedded into the

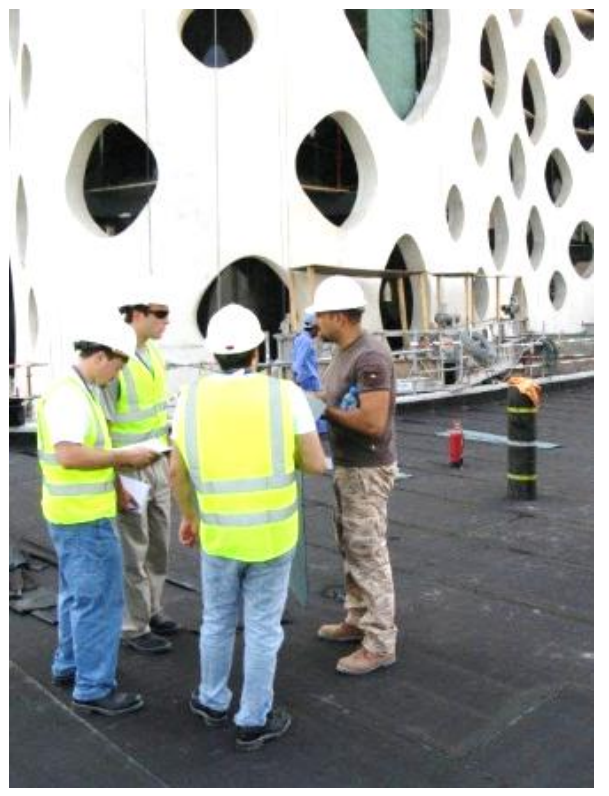

Picture 1: Students listening to instructions from the Project Manager at a job site. curriculum in many different ways. ${ }^{3}$ In addition students need opportunities to understand and appreciate basic cultural differences and similarities around the world and to develop sufficient knowledge to spur a life-long curiosity for understanding other cultures. A unique program was created in 2008 to provide students essential competencies for the global civil engineers. Assessment data to date demonstrates that the integration of an internship abroad and social-cultural learning opportunities can add significant value to the student's accomplishment of global engineering learning outcomes.

\section{Background Literature}

In the last half of the $20^{\text {th }}$ century and especially during the last two decades, globalization has gained momentum. ${ }^{4}$ This increased rate of globalization is attributed to technological advancements which allowed faster and more reliable communications; sharing of information, and global transactions; higher number of trade agreements between multiple nations; development of fast and efficient transportation routes for shipment of goods; and enactment of laws by a number of progressive nations that favor immigration and naturalization. Yates ${ }^{5}$ notes that "modern telecommunication systems link the work in an irrevocable manner, creating a global working environment."

The National Academy of Engineering in its 2004 report "The Engineer of 2020: Visions of Engineering in the New Century"6 also points to globalization of the marketplace as a dynamic greatly impacting the future of engineering. Competitiveness will depend on the ability of engineers and engineering enterprises to adapt quickly to a multi-cultural and multi-national 
work environment. ${ }^{6}$ While intercultural competence is paramount, it is also critical to inculcate a global mindset into all aspects of the work including design, material choice, construction techniques and processes, and construction management. ${ }^{5}$ The Association of American Colleges and Universities released a report in 2008 that included results from two surveys, 2006 and 2007, of employers regarding satisfaction with recent graduates skills and abilities. ${ }^{7}$ These surveys revealed that "fully $63 \%$ of employers believe that too many recent graduates do not have the skills they need to succeed in the global economy.",

This growing cognizance surrounding the impact of globalization has prompted educators to reevaluate the foundational body of engineering knowledge in higher education. Moreover, as engineering education increasingly contemplates the global arena, it is obvious that civil and environmental engineering has been distinctively impacted and has a leading-edge role to play at the individual practicing engineer level and as a discipline. In U.S. institutions, for instance, educators have been urged to reassess their curricula with the demands of globalization in mind. ${ }^{8}$ The increasing demand for international engineering and the changing international nature of engineering work ${ }^{9}$ has also made it clear that, insofar as engineering projects of scale stretch across national boundaries and involve collaborating professionals with very different national, cultural, and educational backgrounds and experiences, lack of training in these matters may adversely impact a project's ultimate success. In short, engineers must focus on improving their abilities to adapt to a global working environment as well as working for or with foreign companies located in the U.S. in order to be competitive. ${ }^{10}$

It is well established that learning to work effectively within the global context of today's world requires technical, professional and intercultural competencies beyond what can be gained in a traditional engineering curriculum. According to Downey et al., a global engineer "possesses the knowledge, ability and interpersonal skills to work effectively with people who define and solve problems differently than they do."11 However, recent graduates of today's engineering programs often lack the necessary professional and interpersonal skills to be successful in a global environment. Students need to integrate cultural awareness, intercultural communication strategies and technical knowledge to enhance understanding and communication with colleagues' and client's but particularly to define and solve the problems to be addressed. ${ }^{11,12}$ Embed into the curriculum should be student development in the areas of teamwork, communication, self-awareness and evaluation, as well as cultural awareness and sensitivity. ${ }^{3}$ Recently psychologists have confirmed that our culture is reflected in the decision-making strategies we use. ${ }^{13}$ Even with the overlay of rigorous formal training in problem-solving, there remains an element of an individual's culture rooted in the process. Essentially, engineers must understand how their own culture impacts their decisions, and develop an appreciation of the cultural dynamics of each project and project team. ${ }^{12}$ Clearly, scholars, industry and practicing engineers are recommending that engineering curricula be designed to equip engineers of the future with the professional and interpersonal skills necessary to join, succeed in, and lead the highly complex, global construction projects of today and the near future. ${ }^{10}$ 


\section{Program Design and Implementation}

Syracuse University has a long tradition of international education. The first group of Syracuse University students studied abroad in China in 1919. The University now has seven overseas centers and facilitates programs in 20 additional countries. The programs offered are a mixture of semester long and short-term curricula resulting in almost half of all Syracuse University students participating in study abroad activities. Unfortunately, only a small number of the study abroad participants are engineering students.

Although Syracuse University has a long tradition of international education, most of these programs only involve sending students to study abroad in overseas institutions or partake in some research or hands-on activities at selected international universities. Unlike these traditional abroad programs, the internship program to be described in this paper is distinctive in a number of ways. For instance:

1. It is designed specifically for engineering students.

2. It offers a series of specially-designed prerequisite training to participating students.

3. It integrates prescriptive and experiential learning in one setting.

4. It involves close collaboration between university faculty and practicing engineers.

5. It provides a synergistic approach for students to apply theory to solve practical problems.

6. It requires students from different countries with diverse background and cultures to interact and work on collaborative projects.

7. It contains a formal social-cultural learning element that is often lacking in a traditional study abroad program.

The practical application and the social-cultural learning opportunities create a cluster of experiences for the professional growth and personal development so necessary to becoming an effective global engineer.

The Dubai summer internship program was conceived of and implemented with technical, logistical and financial support from Mr. Abdallah Yabroudi, Managing Director and CEO of the Dubai Contracting Company (DCC), in Dubai, United Arab Emirates (UAE). Mr. Yabroudi is an alumnus of Syracuse University (1977) and in discussions with the then Department Chair Dr. Eric Lui and one of Mr. Yabroudi former professors Dr. Samuel Clemence, both Laura J. and L. Douglas Meredith Professors for Teaching Excellence, the idea for the internship was developed in the spring of 2007. 


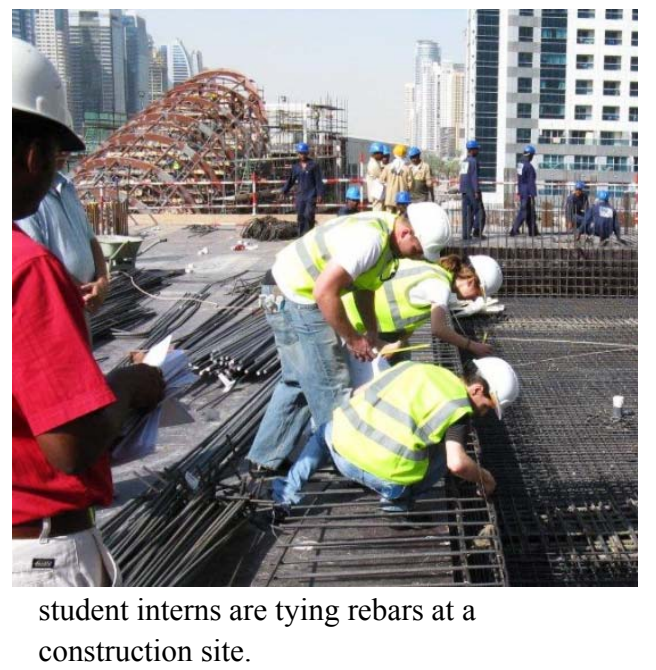

construction site.
The internship program was designed with this global context in mind. One of the main elements of the program is to engage American and Middle Eastern engineering students to work together in a summer internship in Dubai, UAE, under the auspices of DCC and the Department of Civil and Environmental Engineering at Syracuse University. The CEO and staff of DCC, working in conjunction with Syracuse University faculty members, designed the curriculum and instructional materials.

The internship program consists of two distinct but synergistic components: The first component is designed to expose students to the construction and development operations as well as business practices of

one of the fastest growing cities in the Middle East - Dubai. Since 2008, twenty-four Syracuse University civil and environmental students have participated in the program. These Syracuse University students, working with a cohort of an equal number of Middle Eastern students, underwent intensive training in contract negotiation, bidding and tendering, engineering and onsite practices, work progress, construction techniques, and management concepts from DCC management and staff with input from an accompanying Syracuse University faculty member. During the entire duration of the internship, which lasts five to six weeks, American and Middle Eastern students work side-by-side on teams in a collaborative setting that details the conception to completion of a building project. The second component is a series of seminars given in the spring semester before the summer internship. These seminars are specifically designed to provide participating students with the opportunity to learn about the history, geography, culture, political systems, traditions, languages and customs of the Middle East and the Gulf area as well as to get an overview of the construction projects and the different geotechnical and structural engineering systems that they will see on site prior to leaving for the internship. Both components are aimed toward creating an environment for professional growth and personal development. Through a combination of learning and discussion sessions at DCC corporate headquarters and hands-on experience on actual project sites, students learn the detailed workings of the contracting and construction industry in Dubai and the region. Since American and Middle Eastern students work side-by-side on team projects, the program also serves to foster cultural understanding and mutual respect for all participants. The program has been extremely successful and since its inception four years ago more than sixty students from three universities - Syracuse University, Lebanese

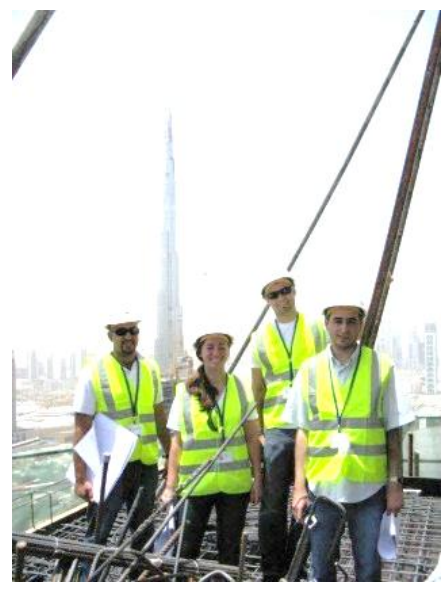

Picture 3: American and Middle Eastern students on an active floor of a building under construction. The building in the background is Burj Khalifa. American University and American University in Dubai - have 
completed the program. Each participating student receives three credits for the internship. For Syracuse University students, one credit is earned for each of the two components described above plus one credit for a formal report and presentation. Thus, a total of three credits which cover (1) the spring pre-trip seminar series, (2) the summer internship, and (3) the fall post-trip activities that involve writing a formal technical report and giving a presentation on campus to students who are not selected to participate.

\section{Key Design Elements}

The Dubai internship program is designed to expose students to the operations and physical realities of one of the leading construction firms in the UAE. The internship program alone is an incredible opportunity for young scholars. There are, however, two elements that make this program very unique. In the spring semester, just prior to the summer internship component, students attend an eight seminar series designed to familiarize themselves with the history and culture of the Middle East and the gulf area. Students explore the practical implications of cultural differences on teamwork, professional communication, and construction and project management. The seminars are presented by guest speakers from a wide variety of programs, disciplines and backgrounds. The students learn about a wide range of socio-cultural topics touching on religion, customs, values, manners, differing viewpoints on the roles of men and women, geography, history, languages, politics and governments. In addition, they discuss how to link theoretical topics learned in coursework with the practical experience component of the internship within the context of the Middle East. The interdisciplinary and socio-cultural awareness elements make these seminars different from other engineering internship programs.

Another special element of this internship is that while in Dubai, instruction is provided almost exclusively by the management and technical staff of the Dubai Contracting Company (DCC). While formal instruction is conducted inside the headquarters of DCC in a technology classroom specifically built for this internship, a series of field trips to construction sites, concrete batch plants, material fabrication shops, and architectural and engineering offices are also arranged so

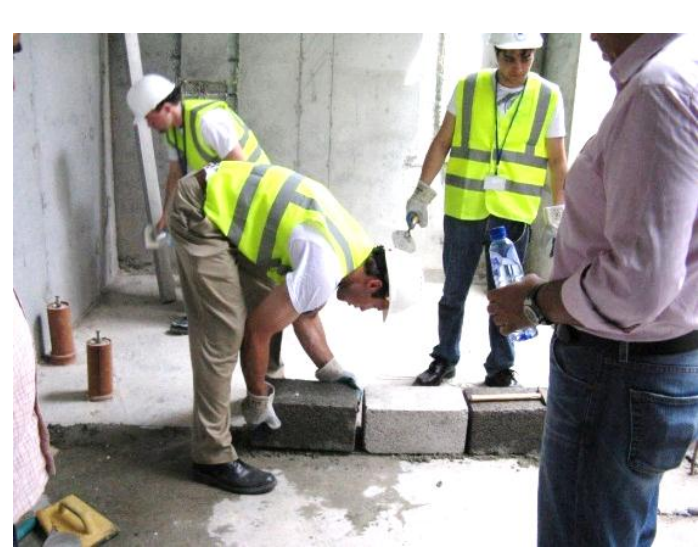

Picture 4: Under the supervision of Mr. Yabroudi, internship participants are learning how to build a masonry blockwall. participating students will have ample opportunities to learn from and interact with construction managers, project engineers and field technicians who are intimately involved in these construction projects. On a given day, typical activities include construction site visits and hands-on work in the morning, formal lectures in the early afternoon, and collaborative student work and presentations in the late afternoon. During weekends and on specific days, participants are taken to various places to engage in social-cultural learning. Some of these cultural tours in the UAE have included visits to the Dubai Museum, the Burj Khalifa, the Palm Islands, 
the surrounding desert areas as well as other Emirates. In addition, each year a special trip outside UAE has been arranged. These special trips have included visits to Amman, the Dead Sea, the World Heritage site at Petra in Jordan; Istanbul, Turkey; and New Delhi and Agra (Taj Mahal) in India.

Accommodations are arranged for by DCC in a suitable apartment/extended living facility. Because American and Middle Eastern students share living quarters, informal/social interactions outside of the classroom are possible and are encouraged. Transportation during program hours is provided by DCC. A cash allowance of US $\$ 1000.00$ is provided to each student to cover per diem expenses such as meals, transportation outside program hours, entertainment, etc., during the internship period. In addition, students are provided with safety equipment, a cell phone, desk space and a laptop computer for use during the internship. A Syracuse University faculty member is on site with the students throughout the entire internship experience.

Students are required to contribute regularly through various activities that may involve question and answer periods, presentations, research or problem solving exercises, hands-on work at visited sites, etc. Some of the internship experiences have been videotaped and recorded on a DVD for use as educational tools. Throughout the internships, students are required to keep a journal with daily entries summarizing topics covered during the day, unique experiences and learning outcomes that were achieved. A blog has also been developed and is updated periodically during the internship period to allow students who are not selected to participate in the program the opportunity to engage in vicarious learning. The blog address is http://dsipprogram.blogspot.com/. Upon completion of the internship, the students are required to give a presentation of their experiences synthesizing the professional and socio-cultural knowledge gained during their time away. This presentation is then given to other engineering students to allow for a spread of knowledge.

The success of the internship has been recognized by our parent and alumni networks and has led to the funding and establishment of another internship with a slightly different design. This second internship was initiated and designed by Dr. Sam Salem, the Yabroudi Chair Professor of Sustainable Infrastructure Systems at Syracuse University, in 2011. It was sponsored by Mr. Abdelmohsen Al-Omran, a banker and parent of a current undergraduate student, and an alumnus Mr. Micheal Venutolo (1977), CEO of Raymond International, a leading global engineering and construction company focused on pipeline installation and

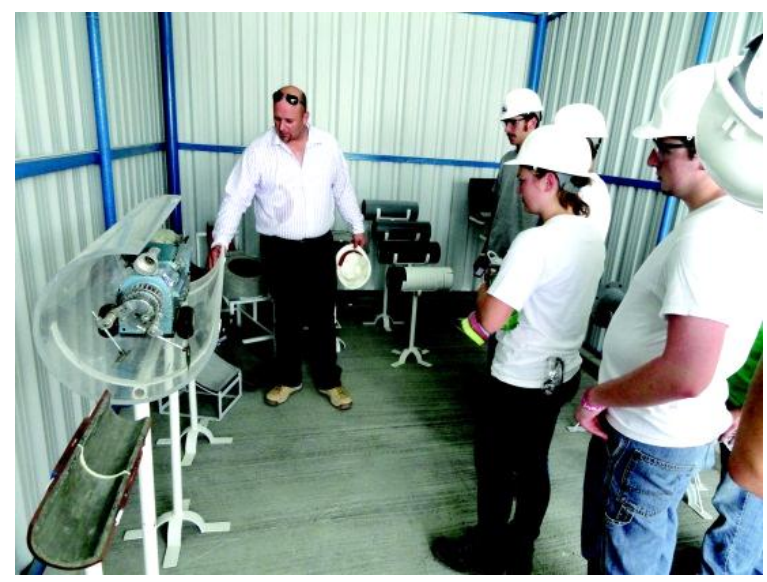

Picture 5: Students at a Raymond International job site in UAE, listening to instructions on cement pipe lining. 
maintenance. These sponsors expressed an interest in funding a global initiative through the College that would benefit the Middle East and include Syracuse University Engineering students. Six civil and environmental engineering students traveled to the United Arab Emirates for two weeks during the summer of 2011. Raymond International headquarters is in Bahrain, and the internship was originally designed to take place in that country. However, civil unrest in 2011 necessitated moving the internship to the United Arab Emirates.

This second internship program was designed to expose students to the issues and operations of providing potable water in arid regions. The targeted focus of this internship in addition to the overlay of global engineering seminars and experiences makes this model one-of-a-kind as well. Most drinking water in the Arabian Peninsula Countries is provided through desalinating seawater. While water generated through non-desalination methods costs about $\$ 0.30$ per cubic meter (for production and transmission), desalinated water costs about $\$ 2$ per cubic meter. The financial burden on governments will worsen in the years ahead as water consumption is rising; driven by rapid industrial development and population growth. As a result, some States are now giving serious attention to how demand can be brought under control. One solution is to improve sustainability and asset management. Water loss via distribution through aged, broken and corroded pipes is also a topic of the program. Students study these water issues as part of their internship. The six students who participated in this internship last summer travelled to different parts of the country, touring job sites and learning up close about clean water production and related engineering projects. As one student said "You can learn all the technical things in school, but you're never going to understand the full process until you see it firsthand." They also visited a desalination plant, steel pipe factory, and corrosion coating and lining plant, as well as watched state-of-the-art water transmission systems being constructed in remote desert locations. The key components of this program are participation in the same seminar series for the Dubai internship on the history and culture of the Middle East and the completion of a technical report upon return from the two-week internship. A total of two credits are earned.

While the students spend most of their time on the job, they also have opportunities to explore and learn about the culture of the area. Between assignments the students visit other cities and take tours of some of the breathtaking sights in the area. Examples include the Burj Khalifa, the world's tallest skyscraper; a Formula One racetrack; the Burj al Arab, the world's only sevenstar hotel; and the Sheikh Zayed Grand Mosque, one of the largest mosques in the world.

It wasn't only the students who learned valuable lessons from the experience. For example, cultural differences were initially a concern for both sides. As Mr. Venutolo said, "At first, some people in my company were intimidated. They wondered what we could possibly teach smart American engineering students." The students had similar concerns. "In U.S. internships, you have an idea of how people are going to act, so you go straight to the technical aspects of how to do the job. In UAE, we had to take time to learn the culture, adjust to the process, and figure out how to work together." This internship opportunity will be offered to another six students during the summer of 2012 . 


\section{Impact on Essential Competencies for Global Engineering}

By the fall of 2010, three cohorts of students had participated in the Dubai Internship. To assess the impact of the program on the professional, cultural and interpersonal skill sets gained through the seminar series and the summer internship, a formal survey was conducted in the spring of 2011. The information mined in this effort was substantial. After a review it was decided that it would be more beneficial to use a pre/post assessment strategy to evaluate program effectiveness for the 2011 Dubai and Raymond International internship programs. The primary objective here is to explore how effective the pre-trip seminars and the internship experience are in preparing students to practice engineering in global situations.

\section{Student Participation}

\begin{tabular}{|c|l|c|c|}
\hline \multicolumn{4}{|c|}{ Table 1: Assessment Group Composition } \\
\hline \multicolumn{2}{|c|}{ Group Composition } & $\begin{array}{c}\text { Pre Internship } \\
\text { Survey and Focus } \\
\text { Group }\end{array}$ & $\begin{array}{c}\text { Post Internship } \\
\text { Survey and Focus } \\
\text { Group }\end{array}$ \\
\hline \multirow{2}{*}{ Group 1 } & $\begin{array}{l}\text { (Dubai internship) } \\
\text { Summer 2010 }\end{array}$ & Not conducted & $\begin{array}{c}6 \text { students } \\
\text { 4 male, 2 female }\end{array}$ \\
\hline \multirow{2}{*}{ Group 2 } & $\begin{array}{l}\text { (Dubai internship) } \\
\text { Summer 2011 }\end{array}$ & $\begin{array}{c}\text { 6 students } \\
\text { 4 male, 2 female } \\
\text { (Raymond Int'l } \\
\text { internship ) } \\
\text { Summer 2011 }\end{array}$ & $\begin{array}{c}\text { 6 students } \\
\text { male, 2 female }\end{array}$ \\
\hline 6 students & $\begin{array}{c}\text { 6 students } \\
4 \text { male, 2 female }\end{array}$ \\
\hline
\end{tabular}

who were eligible to apply for the 2010 Dubai internship was 49 . There were a total of 47 eligible senior students for the second cohort of interns from the 2011 Dubai and Raymond International internships. As a result in $201125 \%$ of the senior class participated in one of the internship programs. Almost all of the students involved in both groups had traveled previously and a smaller number had families from other countries, had lived abroad and/or spoke a second language. Most wanted to travel more and expressed a deep interest in the Middle East. These students came to the program with the cultural curiosity to confidently participate.

\section{Methodology}

The assessment tool was designed and conducted by Ms. Sharon Alestalo, Program Director of Women in Science and Engineering/SU ADVANCE and Dr. Shobha Bhatia, Laura J. and L. Douglas Meredith Professors for Teaching Excellence. It is in two parts and, with the exception of a scenario response used only in the post-internship survey, remained consistent for all assessment sessions. First, a handwritten, anonymous survey was administered at the beginning of the assessment session. The brief survey gathered data about prior familiarity with 
intercultural situations through travel, family, and competence in a second language. Each student was also asked to rate their academic and professional growth in the areas of problem solving, teamwork, interpersonal communication, self-awareness and self-evaluation, and the ability to place themselves in someone else's shoes (empathy). For the post-internship survey the only addition was a scenario response question where students were asked to read a brief scenario and then list and briefly describe five competencies consisting of knowledge, skills, and/or attitudes they learned from their abroad experiences that would help them in the global scenario presented. For the focus group portion a brief introduction to the process was discussed which was followed by the assurance of confidentiality protocols. This series of open-ended questions were asked to address the following questions: 1) Do students become aware of how their own values and perspectives affect their view of other cultures? 2) Are they aware of how cultural differences impact team functioning, project productivity and individual performance? And, 3) By learning about one culture in relation to the work of their internship, do students gain the skills, attitudes and behaviors that are generalizable to other intercultural professional experiences?

\section{Findings}

Pre-Internship Survey: The pre-travel survey/focus group session was conducted in the spring of 2011 with Group 2 after they completed the spring seminar series. Students felt that they showed above average or superior growth in the areas of problem solving, team work, interpersonal communication, and self-awareness over the course of their education career at Syracuse University. One of the essential ingredients to becoming culturally competent is self-awareness and the engagement in opportunities to examine one's own cultural and professional background, as well as biases and assumptions about the culture of others. ${ }^{11} 8$ of the 12 students ranked their ability to place oneself in someone else's shoes (empathy) as above average and 4 as average. No one felt they experienced superior growth in this area. Although ranking their growth in the area of self-awareness was relatively high ( 9 out of 12 ranked it as above average or superior), the depth of knowledge about their own cultural values and beliefs was relatively limited. They did however express a great deal of openness to seeking understanding and appreciation of basic cultural differences and similarities around the world. The students also found that they became more interested in news and current events while attending the seminar and felt they were "more accepting of new things." Many reflected on family and religious differences, both highly valued in the Middle East. Some students felt more aware of how their actions might be perceived through the lens of other cultures. The women students specifically stated that they would be more reserved and more conscious of how their actions will be perceived. The student's personal world view was clearly expanded through the seminars. They understood the need to adjust their behavior in order to succeed. They could also apply this attitude toward professional development; seeking opportunities to work in more interdisciplinary and group settings, and looking at expanding their own creativity. In the end, students felt that the seminars gave them the basics but they would need to be prepared to adapt. 
Post Internship Survey: In assessing their professional and personal growth to date, students from the summer of 2010 Dubai Internship and seminar series (Group 1) felt that they showed above average or superior growth in all areas listed - problem solving, team work, interpersonal communication, self-awareness and the ability to place themselves in someone else's shoes (empathy). Growth in interpersonal communication, teamwork and empathy were ranked as the highest and problem-solving the lowest. Although ranking their growth in the area of selfawareness was relatively high, the depth of knowledge about their own cultural values and beliefs was not as profound as one would expect. Because we did not conduct a pre-internship assessment session with this particular group we are unable to compare the impact of the internship on perceptions of growth.

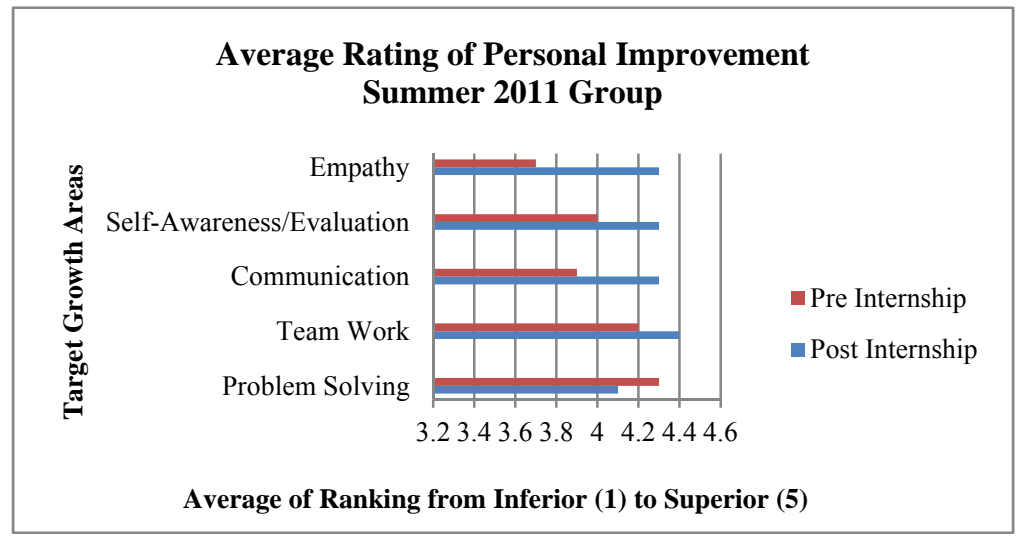

For Group 2 (2011 seminar series and internship) responses to the post-internship perception of academic and professional growth indicated significant change from the spring semester in their ability to place themselves in someone else's shoes (empathy). Observing a construction site laborer one student gained a new perspective noting "I had more money in my pocket at that moment than he made in a month." Figure 1 shows the average rating among the 12 students for the aforementioned professional and personal growth areas. All areas showed growth from the pre-internship assessment to post except in the area of problem solving. Here we believe that students came away with a greater understanding of the gaps in their knowledge as a result of being in the field. "I learned there are many more right answers than what I know." Overall, students in the post-internship assessment session rated their educational and professional growth higher than when they had only participated in the seminar especially in the area of empathy.

In responding to the scenario, students were very clear about the competencies needed to be successful in the described global engineering situation. They felt that communication skills are essential to success in global situations. These skills included listening, understanding and overcoming language barriers, using constant feedback exchanges, making clear directives, and being respectful and professional. Most students felt that having an open mind was also a key attitude and behavior. Operating as an effective team member requires the ability to seek understanding and common ground as well as to combine individual skill sets that will result in the best solution and solid team functioning. Finally, students articulated a wide variety of essential multi-cultural skills such as understanding differences in learning styles and values, assessing for differences in how work is performed, and advance research of the locale and its 
culture to enhance understanding. Personal characteristics like patience, asking effective questions, and demonstrating respect also ranked high as competencies.

Focus Group Findings Summaries: In general the focus group findings as they relate to the initial questions can be summarized as follows:

1) Do students become aware of how their own values and perspectives affect their view of other cultures?

Students clearly had gained a greater appreciation for differences and similarities over the course of all components of the internship. One student said the city is "not so different from ours, but there are cultural differences you learn to respect." However, students felt that they needed more work to fully understand the lens (cultural values, beliefs and behaviors) they use in their professional work, decision making and interpersonal/business interactions. But they also felt that they now have greater insight, cultural curiosity and motivation to continue their work toward becoming culturally competent engineers.

2) Are they aware of how cultural differences impact team functioning, project productivity and individual performance?

Students also seemed to understand that one cannot impose one's beliefs, values and patterns of behavior on others ${ }^{11}$. This is another sign of gaining cultural competence. This became obvious to them when they lived, attended classroom activities and worked with students from the Middle East. The different approaches to learning and projects helped underscore the importance of being open minded to other ideas and ways of working as well as how to find common ground with team members. "I am more open and responsive to new ideas." Among the participants, team work and communication were considered to be the most essential competencies necessary to work globally. "I feel that I am relatively prepared to work with other colleagues because of the team-work skills I developed." Students recognized that these skills need to be heavily overlaid with understanding, respect, adaptability and open mindedness. Students also recognized their substantial gains in understanding and appreciating their profession as a result of the internship experience. "I can identify problems better and find solutions to them." "The experience taught me to be a more practical problem solver." For the first time students considered other essential qualities necessary for effective engineering solutions including context, culture, materials and economic/labor considerations.

3) By learning about one culture in relation to the work of their internship, do students gain the skills, attitudes and behaviors that are generalizable to other intercultural professional experiences?

These programs have significantly impacted how students view themselves and their experiences. One student said "I have learned to assess and evaluate myself as an engineer and as 
a leader, which is important when working for a large, multinational corporation." Another learned after observing laborers and professionals from multiple countries that "the most beneficial attitude is to recognize that all people regardless of where they are from share equal value to a project." Several others used the word inspired - inspired to "initiate tasks more frequently", "act as a leader" or to see the "beauty of new experiences." They also have the ability and confidence to adapt and transfer what they have learned, as one student said, "I understand people come from different cultures and backgrounds and (I) can adapt to that." The students not only understand but embrace the future of intercultural and global engineering.

\section{Next Steps}

When returning interns were asked how we could improve the general civil and environmental engineering curriculum to include more information about global engineering, they quickly articulated a series of interventions including increased opportunities to visit construction sites, more opportunities to work across engineering and other disciplines, and increased references in classes regarding how cultures, the environment and economics impact materials and construction practices. It is apparent that these students have gained a greater sensitivity to the broader context that all engineers must operate within. Below are some steps that we have taken or are going to implement in the foreseeable future:

1. One limiting factor of these internship programs is the expenses and logistical complexity of abroad programs. It is not feasible to provide these intensive and effective internship models of global engineering development to a large group of students. Our next task is to determine what we can do to mimic as best as possible the experiences of these interns so a larger number of students can benefit. On this front, the original sponsor has provided additional funding to allow all civil and environmental seniors to participate in a multi-day field trip to visit project/construction sites in the U.S.

2. In addition to the field trip, an experiential-based civil engineering workshop is being designed to provide students with hands-on experience in construction methods such as tying and fixing rebars, placing concrete and block work, doing plaster work, fixing tiling and painting, etc.. A textbook is also being prepared based on the notes from the internship describing construction engineering practice in a global environment.

3. Furthermore, we are seeking sponsorship for a seminar series that will bring alumni with global engineering and construction expertise to campus focusing on their experiences in working globally and in adapting to differing cultural norms, social expectations and engineering approaches.

4. The presentations by the interns after their experience in the Dubai and Raymond International internships will be made a requirement for all students to attend so they can gain a sense of engineering construction in a global environment. This combination of 
local construction site visits, hands-on experience and seminar series, combined with the presentations by returning interns, will embed global engineering education more deeply into the learning outcomes for all students.

5. In addition, the new 2011 pilot of the Raymond International Internship Program was extremely successful and provided another excellent, engineering-specific opportunity for civil and environmental engineering students. It was designed to expose six senior students to the issues and operations of providing potable water in arid regions. It is slated to continue in 2012.

Based on the success of these internships and the willingness of alumni to support other internships, the ultimate goal is to secure financial and business sponsorships to expand internships to other parts of the world including India, China, and Central and South America, etc.

\section{Conclusions}

The importance of working effectively as global engineers is critical for civil and environmental engineering. Summer internships spent abroad in engineering-specific settings after participating in socio-cultural seminars is a highly effective means of educating global engineers. The two internships described here are clear examples of how academic and industry/alumni partners can collaborate to enhance education. They demonstrate how focused experiential learning opportunities can create a more nuanced and deeper scholarship for academic, professional and personal development.

1. These innovative summer internship programs that started in 2008 (Dubai Contracting Company) and 2011 (Raymond International) have profoundly impacted more than 60 United States and Middle East students. Program evaluations have shown that students have moved from an intellectual understanding to a fully integrated understanding of their profession and interpersonal relationships in global settings.

2. The internship experience has had a profound impact on the participating students' understanding of civil and environmental engineering and has given them an awareness of other cultures and increased respect for differing points of view.

3. These programs have provided an essential service to the engineering profession by providing students with a solid foundation of genuine openness, cultural curiosity and cultural understanding, as well as a greater appreciation for the power of communication, interpersonal relationship skills, organization, and team membership. All these are essential skills for a global engineer. These young scholars have gained a global perspective and a solid foundation for a successful and meaningful career. 
4. Through the assessment process it has become clear that seminars alone do not provide students with sufficient information to become culturally competent global engineers. It does however open the door for increasing understanding and assimilating the internship experiences. From the discussion, the experiential component provides the opportunity to expand and refine global engineering competencies, thus allowing the student to fully integrate their engineering education. The seminars, when given in conjunction with the practical application, help inculcate the global competencies necessary for today's engineers. In other words, understanding what and when to use effective personal and professional strategies in a culturally competent manner comes with education, cultural awareness and experience.

\section{Acknowledgment}

The authors would like to acknowledge and thank Mr. Abdallah Yabroudi, Managing Director and CEO of the Dubai Contracting Company, for his vision and leadership in establishing, funding and engaging in the learning processes of the DCC SU Internship Program. Through his wonderful generosity and unselfish support this program has profoundly affected all of the students and faculty involved in this distinctive program and has fostered a better understanding of global engineering. The authors would also like to express our appreciation to Mr.

Abdelmohsen Al-Omran, parent of a current student, and alumnus Mr. Michael Venutolo of Raymond International who saw the potential in the Dubai internships and helped to create and support another model for successful development of future global engineers. Through the synergistic efforts of these gentlemen, unique, meaningful and highly effective learning opportunities were crafted.

\section{References}

1. Pennoni, C. R. (1998). "Managing your career in an era of change." Journal of Professional Issues in Engineering Education and Practice, 124(3), 75-77.

2. Galloway, P. T. (2003). "The mission of the civil engineer in the movement of globalization." Leadership and Management in Engineering, 3(3), 122-127.

3. Harris, M. and Cullen, R. (2008). "A model for curricular revision: The case of engineering." Innovation in Higher Education (2009) 34,. 51-63.

4. Sheehan, M. (2010). "Globalization: conundrums and paradoxes for civil engineering." Leadership and Management in Engineering, 10(1), 10-15.

5. Yates, J.K. (2007). Global engineering and construction. Hoboken, NJ: John Wiley \& Sons, Inc.

6. "The Engineer of 2020: Visions of Engineering in the New Century," (2004) Washington DC: National Academies Press. Retrieved from www.nap.edu on April 8, 2011.

7. “Our Students' Best Work: A Framework for Accountability Worthy of Our Mission," (2008). Washington, D.C.: Board of Directors, Association of American Colleges and Universities.

8. Cheah, C. Y. J., Chen, P.-H., and Ting, S. K. (2005). "Globalization challenges, legacies, and civil engineering curriculum reform." Journal of Professional Issues in Engineering Education and Practice, 131(2), 105-110. 
9. Ircha, M. C. (1999). "Multinational engineering consortia: selecting team members." Journal of Professional Issues in Engineering Education and Practice, 125(4), 152-157.

10. Del Vitto, C. (2008). "Cross-cultural "soft skills" and the global engineer: Corporate best practices and trainer methodologies." Online Journal for Global Engineering Education, 3(1), Article 1.

11. Downey, G.L., Lucena, J. C., Moskal, B., Parkhurst, R., Bigley, T., Hays, C. Jesiek, B., Kelly, L., Miller, J., Ruff, S., Lehr, J., and Nichols-Belo, A. (2006). "The globally competent engineer: Working effectively with people who define problems differently." Journal of Engineering Education. 95(2) (April 2006), 107-122.

12. Ayokanmbi, F.M. (2011). "Competencies for global engineers and technologists." Journal of Industrial Technology. 27(1) (March 2011), 1-6.

13. Güss, C.D. and Dörner, D. (2011). "Cultural differences in dynamic decision-making strategies in a nonlinear, time-delayed task." Cognitive Systems Research, 12(2011), 365-376. 